\title{
Penoscrotal elephantiasis: Case report
}

\section{Anna Jędrowiak, Magdalena Oszukowska, Anna Żuchowska, Katarzyna Tabara, Anna Szewczyk, Mirosława Kuchciak-Brancewicz, Andrzej Kaszuba}

Department of Dermatology, Pediatric Dermatology and Oncology, Medical University of Lodz, ul. Kniaziewicza 1/5, 91-347 Lodz, Poland

Corresponding author: Anna Jędrowiak, MD, E-mail: aniaula@o2.pl

\begin{abstract}
Genital elephantiasis is characterized by massive growth of genitals as a result of chronic lymphedema caused by numerous infectious and noninfectiuos triggers. In most cases it occurs in filarial endemic zones and is rarely encountered in developed nations. Herein, we report a case of 33-year-old previously healthy patient who presented with rapid penoscrostal enlargement and systemic signs due to probable streptococcal contagion after a surgical treatment of phimosis subsequently complicated with chronic penoscrotal lymphedema. Genital elephantiasis is usually irreversible with systemic therapy alone and frequently requires surgical procedures following the acute stage of the disease.
\end{abstract}

Key words: Penoscrotal elephantiasis; Penile elephantiasis; Penile cellulitis

\section{INTRODUCTION}

Elephantiasis is a symptom of many diseases characterized by thickening of the skin and underlying tissues [1]. The term "elephantiasis" was first used by Celsus (30 BC-50 AD) to describe bizarrely enlarged elephant-like lower limb due to lymphatic obstruction. It was also known as satyriasis, sarcocele or leontiasis. Subsequently, the term was used to describe the similar growth of the arm, chest, breast, penis, scrotum or vulva $[2-3]$.

Genital elephantiasis usually affects young and productive individuals. Chronic lymphedema is disabling with physical and psychological morbidity and complications, including impaired hygiene, sexual disfunction, problems with walking, urinary incontinence and immobility. The majority of cases are due to filarial parasites Wucheria bancrofti, less often due to bacterial sexually transmitted infections, such as lymphogranuloma venerum and donovanosis. The other, rare causes include leishmaniasis, tuberculosis, pelvic and abdominal or haematological malignancy as well as its therapy, continuous ambulatory peritoneal dialysis or dermatological diseases, most commonly lichen simplex chronicus and hidradenitis suppurativa [3-7].

An estimated 120 million people in Southeast Asia and Africa are infected with lymphatic filariasis. Of these, 25 million men have genital disease and 15 million women have lymphedema or elephantiasis of the leg. One-third of infected people live in India, one third in Africa, and the remainder in South-Asia, the Pacific and the Americas [8]. Filarial elephantiasis of vulva is uncommon and comprises 1-2\% of the total cases of filarial elephantiasis [9].

Cellulitis and erysipelas of penis are uncommon clinical conditions, most often seen in young individuals and presented with local and systemic symptoms that progress rapidly. It needs to be differentiated from sexually transmitted infections.

\section{CASE REPORT}

We report a case of 33-year-old male who was aware of redness and swelling of the penis and scrotum with reccuring fever for 2 months prior to a consultation at our department. In October 2014 patient underwent

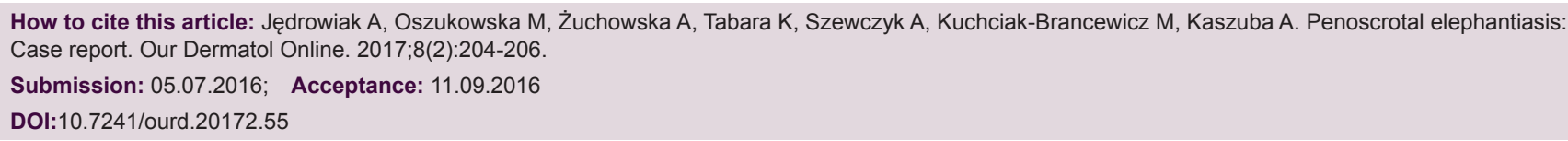


urological surgery for phimosis (Schloffer technic]. Several hours before the operation patient had fellatio performed without condom by his wife who was suffering from strep throat at that time. Two days later patient presented with paraphimosis, severe pain, redness, swelling of penis and scrotum and fever up to $39^{\circ} \mathrm{C}$. The patient was treated firstly at Urology Department where prepuce was restored to its original postion, surgical penoscrotal and suprapubical drainage was performed. He was also administred of broadspectrum antimicrobial agents and hyperbaric oxygen therapy but it all proved to be ineffective. Subsequently, the patient visited our department (Figs. 1 and 2). On examination, body temperature was normal, the penis and scrotum were massively edematous and enlarged, the skin was erythematous and tender. No vesicles or pustules were seen and there was no discharge. Inguinal lymph nodes were enlarged. There was no history of diabetes mellitus and the patient was not taking any regular medications. During last year patient travelled several times to Asia. His blood test revealed an elevated C-reactive protein (103 mg/dl). Laboratory studies did not reveal evidence of a systemic disease (complete blood count, erythrocyte sedimentation rate, RPR, HIV, Chlamydia trachomatis, Neisseria gonorrhoeae, microfilariae in blood smear, fungal and bacterial cultures, chest X-ray, abdominal ultrasonography were normal). The clinical history and absence of other etiologies suggested diagnosis of erysipelas complicated with elephantiasis. The patient was administered of intramuscular penicillin, oral levofloxacin and suspensory.

In our patient only a slight progress was monitored after a month of therapy (Figs. 3a and 3b). Penoscrotal edema reduced inconciderably, penis and scrotum remained erythematous. Most cases of erysipelas usually response to antibiotic therapy rapidly. In our patient penile cellulitis was complicated with chronic lymphedema which worsened the response to treatment.

\section{DISCUSSION}

Penile cellulitis is rare clinical condition, mainly encountered in sexually active uncircumcised young men. Streptococcus agalactiae (the Lancefield group B beta haemolytic streptococcus) is the usual causative organism, although less virulent organisms can rarely trigger the disease, especially in immunocompromised patients [10]. Streptococcus pyogenes (the Lancefield group A beta hemolytic streptococcus) is known as a

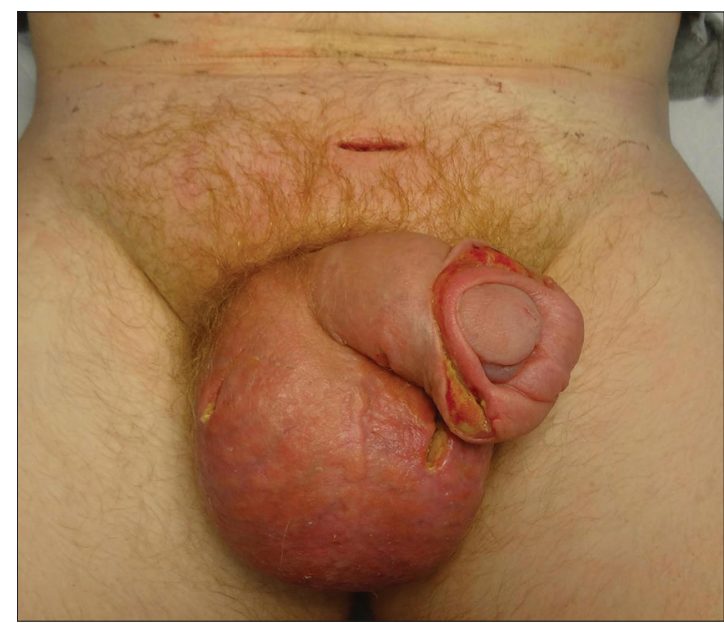

Figure 1: A month after surgery of phimosis- penosctrotal elephantiasis with surgical incision of penis.

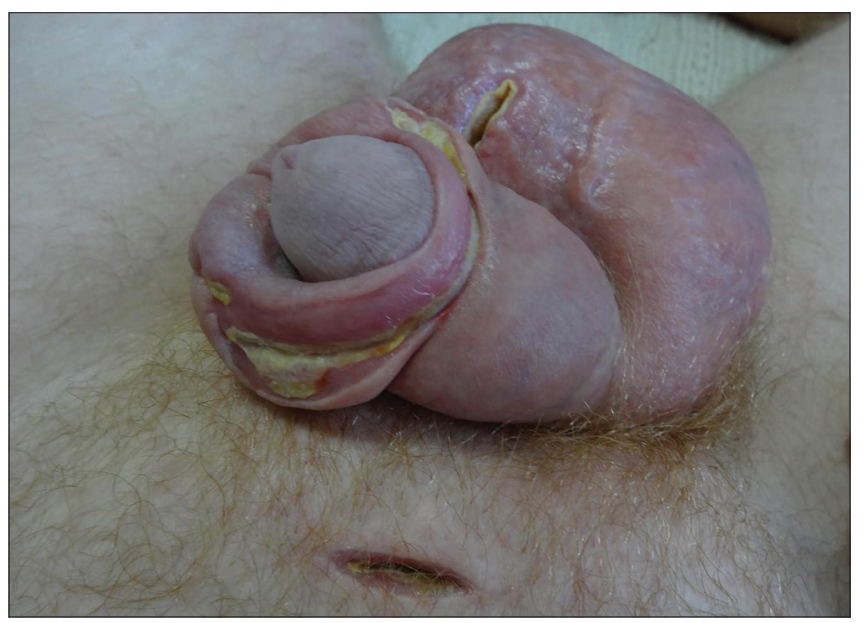

Figure 2: A month after surgery of phimosis- surgical incision of penis.

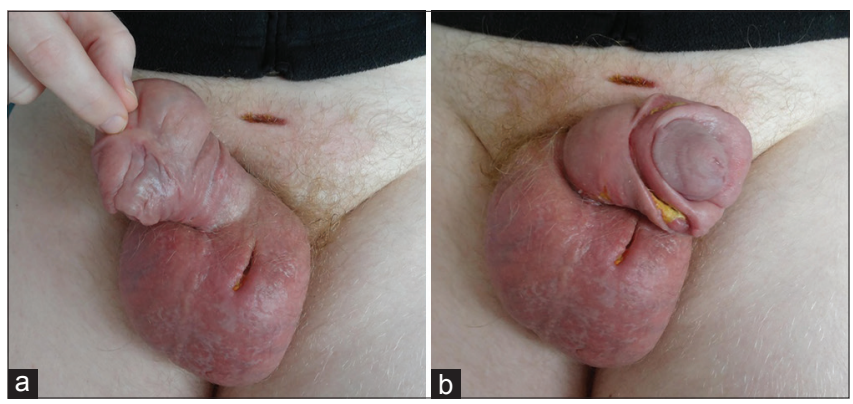

Figure 3: ( $a$ and $b)$ After a month of therapy.

cause of pharyngitis, erysipelas and impetigo. However, cases of severe balanitis due to $\mathrm{S}$. pyogenes aguired during fellatio performed by commercial sex workers have been reported [11-13].

Group B beta-haemolytic streptococci are known to colonise the throat and lower female genital tract; prevalence is $4 \%$ to $18 \%$ [14]. Other causative organisms 
include Staphylococcus, Chlamydia trachomatis, Escherichia coli, Klebsiella pneumoniae, Bacteroides spp., Candida and anaerobic streptococci. Other host factors such as alcoholism, trauma (including surgery), intracavernosal injection for erectile dysfunction penile prosthesis and immunosuppression may predispose to penile cellulitis [10].

Cellulitis of the penis usually presents with penile swelling and pain, and may be associated with discharge, urinary symptoms, fever and inguinal lymphadenopathy. Sexually transmitted infection should be ruled out and purulent discharge, if present, sent for Gram staining and culture. Abscess should be excluded by imaging studies [10].

Gupta et al. reported erysipelas as a frequent complication in patients with genital elephantiasis due to impaired defense mechanism of the skin related to chronic lymphatic obstruction and compromised blood supply. Contrarily postinflammatory changes from recurrent or prolonged streptococcal lymphangitis and cellulitis leads to permanent obstruction of lymphatic channels, which escalates fibrogenesis. These processes lead to destruction of lymph nodes and subsequently to lymphedema or elephantiasis. Such patients benefit from long term penicillin therapy and vaccination against streptococci $[3,15]$.

The objectives of treatment are to reduce edema, restore shape and normal sexual and urinary function, and prevent inflammatory episodes, for example recurrent cellulitis [16]. Surgery is the only effective option for a group of patients in whom the disorder is disabling and persistent. Operations fall into two categories: bypass procedures and reduction procedures [3].

Although our patient improved partially, the potential for complete resolution remains poor.

\section{CONCLUSION}

Cellulitis of the penis is an uncommon condition, seen rarely as an acute case in urology. Both with penoscrotal elephantiasis are still a diagnostic and therapeutic challenges. Although the majority of worldwide genital lymphoedemas are of infectious origin, in industrialized countries genital elephantiasis is usually attributed to surgery, irradiation or malignancies. Since people are travelling all over the world broad spectrum of causative organisms should be considered in case of penile cellulitis. Administration of appropriate antibiotics resolves the local and systemic symptoms and avoids complications. Genital elephantiasis may become a major burden to affected people thus the importance of thorough clinical examination can not be overestimated.

\section{Consent}

The examination of the patient was conducted according to the Declaration of Helsinki principles.

\section{REFERENCES}

1. Yimer M, Hailu T, Mulu W, Abera B. Epidemiology of elephantiasis with special emphasis on podoconiosis in Ethiopia: a literature review. J Vector Borne Dis. 2015;52:111-5.

2. Mohan H, Bisht B, Goel P, Garg G. Vulval elephantiasis: a case report. Case Rep Infect Dis. 2012;2012:430745.

3. Gupta S, Ajith C, Kanwar AJ, Sehgal VN, Kumar B, Mete U. Genital elephantiasis and sexually transmitted infections-revisited. Int J STD AIDS. 2006;17:157-65.

4. Brotherhood HL, Metcalfe M, Goldenberg L, Pommerville P, Bowman C, Naysmith D. A surgical challenge: Idiopathic scrotal elephantiasis. Can Urol Assoc J. 2014;8:E500-7.

5. Padmavathy L, Lakshmana Rao L, Chockalingam K, Ethirajan L. Elephantiasis of the external genitalia: a sequel to cutaneous tuberculosis. Indian J Dermatol. 2009;54:52-5.

6. Nelson RA, Albert GL, King RL Jr. Penile and scrotal elephantiasis caused by indolent Chlamydia trachomatis infection. Urology. 2003;61:224.

7. Chintamani, Singh J, Tandon M, Khandelwal R, Aeron T, Jain S, et al. Vulval elephantiasis as a result of tubercular lymphadenitis: two case reports and a review of the literature. J Med Case Rep. 2010;4:369.

8. Lakshmidevi M, Sampath G, Shreedhar V. Recurrent Unilateral Vulval Elephantiasis: A Case Report. J Family Reprod Health. 2014;8:87-9.

9. Khanna NN, Joshi GK. Elephantiasis of female genitalia: case report. Plast Reconstr Surg. 1971;48:379-81.

10. Mallikarjun B, Nanik V. Cellulitis of the penis: a case report, BMJ Case Rep. BMJ Case Rep. 2009;2009. pii: bcr01.2009.1457.

11. Aldeen T, Mantell J. Penile cellulites. Hosp Med. 2000;61:580-1.

12. Sakuma S, Komiya H. Balanitis caused by Streptococcus pyogenes: a report of two cases. Int J STD AIDS. 2005;16:9.

13. Drusin LM, Wilkes BM, Gingrich RD. Streptococcal pyoderma of the penis following fellatio. Br J Vener Dis. 1975;51:61-2.

14. Rowen D. Streptococci and the genital tract. Int J STD AIDS. 1993;4:63-6.

15. Nayak S, Acharjya B, Devi B, Pattnaik S, Patra M. Cerebriform elephantiasis of the vulva following tuberculous lymphadenitis. Indian J Dermatol Venereol Leprol. 2008;74:188.

16. Mortimer PS. Therapy approaches for lymphoedema. Angiology. 1997;48:87-91.

Copyright by Anna Jędrowiak, et al. This is an open access article distributed under the terms of the Creative Commons Attribution License, which permits unrestricted use, distribution, and reproduction in any medium, provided the original author and source are credited.

Source of Support: Nil, Conflict of Interest: None declared. 